\title{
A Mathematical Approach to Study Temperature Regulation of Human Body Due To Different Arterial Blood Temperature
}

\author{
Yogesh Shukla \\ Mathematics,Amity University MadhyPradesh,india
}

\begin{abstract}
The study of temperature regulation of human body has great importance to understand the physiology of the human body. Skin plays an important role to maintain the body core temperature $\left(T_{b}\right)$ at $37^{\circ} \mathrm{C}$. Any disturbance in the temperature regulation may cause lots of abnormality in the body. In the present paper an attempt has been made to study temperature variations of dermal region of human by changing arterial blood temperature for transient case. The temperature variations are noted at different arterial blood temperature and venous blood temperature tissue of dermal region.
\end{abstract}

Keywords: Rate of metabolism, blood mass flow rate, thermal conductivity, heat generation, finite element method.

\section{Introduction}

Mathematical models have tremendous potential for advancing the understanding of the physical processes involved in medical science and biological processes etc.Body temperature plays an important role to regulate every biological system. Metabolism is main source to generate heat continuously within the human body. If this heat is not lost from the body, then the temperature of body will keep on rising continuously. Thus the body heat is continuously lost to the surrounding. The process which maintains thermal balance between the body and surrounding is known as thermal regulation system of the body.

There are many factors affecting body temperature like atmospheric temperature, the body mass and surface area of the body, Human body is composed of three layers namely sub dermis, dermis and dermis. Due to absence of blood vessels in epidermis, the blood circulation in epidermis is negligible. And dermis blood flow is variable while uniform in subcutaneous tissue. The rate of blood flow in SST region is most variable in comparison to other parts of the body.

Many investigations have been made to study thermal responses in normal and abnormal conditions. Perl (1962) combined differential forms of Flick's perfection principle with heat conduction and matter diffusion equations and metabolic term to obtain equation.He used equation to solve its simple cases by taking all parameters as constant throughout the region. Perl and Hirsch (1966) used this equation to test the transient response for measuring local tissue blood flow on dog and rabbit kidney.Trezek and Cooper (1968) computed thermal conductivity of tissue by taking all parameters as constant.

Cooper and Trezek $(1972, a, b)$ obtain solution of equation in SST region by taking all parameters as constant. Patterson $(1976,1978)$ made experimental attempts, to determine temperature profiles in skin and subcutaneous region.Saxena (1978) solved equation by similarity transformation in SST region.Saxena and Arya (1981) used variation finite element methods to solve the problem of steady state temperature distribution in three layered skin and subcutaneous region. Saxena,AryaandBindra(1987) obtained unsteady state temperature distribution in human skin and subcutaneous tissue region, by using the variation finite method and Laplace transform method.SaxenaandPardasani(1991) discussed the effect oftumor on temperature distribution in human skin.Yadav (1998)solved various types of temperature distribution problem in skin andSST region with thermal injury.

Although in this field lot of work has been done by many mathematician, scientists and other researchers but it is not possible to explain the work of everyone. Results obtained by all mentioned mathematicians,scientists and researchers are much under consideration,but their studies are confined to take constant or average values of arterial blood temperature and venous blood temperature is equal to tissue temperature, which are practically not possible in the skin and SST region.

In the present paper we have taken arterial blood temperature as position dependent and venous blood temperature is also taken variable.

\section{Material and Methods}

Perl's Bio heat partial differential equation in one dimensional transient state case for heat distribution in the tissues of SST region of human body can be written as:

$\frac{\partial}{\partial x}\left(K \frac{\partial T}{\partial x}\right)+m_{b} c_{b}\left(T_{b}-T\right)+\mathrm{S}=\rho c \frac{\partial T}{\partial t}$ 
Here the effect of metabolic heat generation and blood mass flow are given by the terms $\mathrm{S}$ and $m_{b} c_{b}\left(\mathrm{~T}_{\mathrm{b}}-\mathrm{T}\right)$ respectively. $\mathrm{T}_{\mathrm{b}}, \mathrm{K}, \rho, \mathrm{c}, m_{b}$ and $c_{b}$ are body core temperature, thermal conductivity, density and specific heat of tissue; blood mass flow rate and specific heat of blood respectively. Right hand side of eq. (1) shows the storage of heat in tissues. The first two terms of the left hand side represents conduction of heat in the tissues, caused by the temperature gradient and third term is for heat transport between the tissues and microcirculatory blood perfusion. The lastterm represent heat generation due to metabolism. Using (1) a mathematical model for heat flow in living tissues for one dimensional unsteady state case can be written as:

Boundary conditions: The outer surface of the body is exposed to the environment and heat loss at this surface takes place due to conduction, convection, radiation and evaporation. Thus the boundary conditions at the outer surface

$$
-K \frac{\partial T}{\partial n}=h\left(T-T_{a}\right)+L E \quad \text { for } t>0
$$

Where $\mathrm{h}$ heat transfer coefficient, $\mathrm{T}_{\mathrm{a}}$ is atmospheric temperature, $\mathrm{L}$ and $\mathrm{E}$ are respectively, the latent heat and rate of evaporation and $\partial \boldsymbol{T}$ is the partial derivatives of $\mathrm{T}$ along the normal to the skin surface.

the inner surface

$$
T_{V}=q T
$$

Where $\mathrm{q}$ is known constant its value is nearer to 1 .

\section{III.Initial condition}

The outer surface of the skin assumed to be insulated at time $t=0$ and hence the initial condition is given by

$$
T(x, 0)=T_{b}=37^{\circ} \mathrm{C}
$$

If $I_{1}, I_{2}$ and $I_{3}$ are the values of $I$ in three sub-regions then

$$
I=\sum_{i=1}^{3} I_{i}
$$

Now using equation (1),(2)with equation (3), we get

$$
\begin{aligned}
& I_{1}=\frac{K_{1}}{2 a}\left(T_{1}-T_{0}\right)^{2}+\frac{h}{2}\left(T_{0}-T_{a}\right)^{2}+L E T_{0} \\
& I_{2}=\left(T_{2}-T_{1}\right)^{2} E_{1}+\left(T_{2} a_{1}-T_{1} a_{2}\right)^{2} E_{2}+\left(T_{2} a_{1}-T_{1} a_{2}\right)\left(T_{2}-T_{1}\right) E_{3}+\left(T_{2} a_{1}-T_{1} a_{2}\right) E_{4} \\
& +\left(T_{2}-T_{1}\right) E_{5}+E_{6} \\
& I_{3}=\left(T_{3}-T_{2}\right)^{2} F_{1}+\left(a_{3} T_{2}-a_{2} T_{3}\right)^{2} F_{2}+\left(T_{3}-T_{2}\right) F_{3}+\left(a_{3} T_{2}-a_{2} T_{3}\right) F_{4} \\
& +\left(T_{3}-T_{2}\right)\left(a_{3} T_{2}-a_{2} T_{3}\right) F_{5}+F_{6}
\end{aligned}
$$

Where,

$$
\begin{aligned}
& E_{1}=\frac{a_{2} K_{1}-a_{1} K_{3}}{2\left(a_{2}-a_{1}\right)^{2}}+\frac{K_{3}-K_{1}}{\left(a_{2}-a_{1}\right)^{2}}\left(\frac{a_{1}+a_{2}}{4}\right)+\frac{q^{2} M\left(3 a_{2}^{2}+2 a_{2} a_{1}+a_{1}^{2}\right)}{24\left(a_{2}-a_{1}\right)}, \\
& E_{2}=M q^{2} \frac{1}{4\left(a_{2}-a_{1}\right)}, \\
& E_{3}=-\frac{M q T_{b}\left(a_{2}-a_{1}\right)\left(a_{1}+3 a_{2}\right)}{12\left(a_{3}-a_{1}\right)}, \\
& E_{4}=-m q \frac{T_{b}\left(a_{2}-a_{1}\right)}{3\left(a_{3}-a_{1}\right)}-\frac{S}{2},
\end{aligned}
$$




$$
\begin{array}{rl}
E_{5} & =m q^{2} \frac{\left(a_{1}+2 a_{2}\right)}{6\left(a_{2}-a_{1}\right)}, \\
E_{6} & =M\left(\frac{T_{b}}{a_{3}-a_{1}}\right)^{2} \frac{\left(a_{2}-a_{1}\right)^{3}}{8}, \\
F_{1} & =\frac{q^{2} M}{6} \frac{\left(a_{3}^{2}+a_{2}^{2}+a_{3} a_{2}\right)}{\left(a_{3}-a_{2}\right)}+\frac{K_{3}}{2\left(a_{3}-a_{2}\right)}, \\
F_{2} & =M q^{2} \frac{1}{2\left(a_{3}-a_{2}\right)} \\
F_{3} & =-\frac{T_{b} q M\left(2 a_{2}^{2}+3 a_{3}^{2}+2 a_{2} a_{3}-3 a_{1} a_{3}-3 a_{1} a_{2}\right)}{6\left(a_{3}-a_{1}\right)}-\frac{S\left(a_{3}+a_{2}\right)}{2}, \\
F_{4} & =-\frac{T_{b} q m}{2} \frac{\left(a_{3}+a_{2}-2 a_{1}\right)}{\left(a_{3}-a_{1}\right)}-S \\
F_{5} & =\frac{m q^{2}\left(a_{3}+a_{2}\right)}{2\left(a_{3}-a_{2}\right)}, \\
F_{6}= & M\left(\frac{T_{b}}{a_{3}-a_{1}}\right)^{2} \frac{\left(a_{3}^{2}+a_{2}^{2}+a_{3} a_{2}-3 a_{1} a_{2}-3 a_{1} a_{3}+3 a_{1}^{2}\right)^{3}\left(a_{3}-a_{2}\right)}{6}, \\
A_{b} C_{b} & M
\end{array}
$$

Since $T_{3}$ is equal to body core temperature, so we minimize $\mathrm{I}$ for $T_{0}, T_{1}$ and $T_{2}$. Accordingly we get following system of equations:-

$$
L_{1} T_{0}-L_{2} T_{1}=W_{0} \quad ; M_{1} T_{0}+M_{2} T_{1}+M_{3} T_{2}=W_{1} ; \quad N_{1} T_{1}+N_{2} T_{2}=W_{2}
$$

Where,

$$
\begin{aligned}
& L_{1}=\frac{K_{1}}{a_{1}}+h \\
& L_{2}=-\frac{K_{1}}{a_{1}} \\
& W_{0}=\left(h T_{a}-L E\right) \\
& M_{1}=-\frac{K_{1}}{a_{1}} \\
& M_{2}=\frac{K_{1}}{a_{1}}+2 E_{1}+2 a_{2}^{2} E_{2}-2 a_{2} E_{5} \\
& M_{3}=-2 E_{1}-2 a_{1} a_{2} E_{2}+\left(a_{1}+a_{2}\right) E_{5} \\
& W_{1}=E_{3}-a_{2} E_{4} \\
& N_{1}=-2 E_{1}-2 a_{1} a_{2} E_{2}+\left(a_{1}+a_{2}\right) E_{5}
\end{aligned}
$$




$$
\begin{aligned}
& N_{2}=2 E_{1}+2 a_{1}^{2} E_{2}-2 a_{1} E_{5}+2 F_{1}+2 a_{3}^{2} F_{2}-2 a_{3} F_{5} \\
& W_{2}=\left\{2 F_{1}+2 a_{2} a_{3} F_{2}-\left(a_{2}+a_{3}\right) F_{5}\right\} T_{3}-E_{3}+a_{1} E_{4}+F_{3}-a_{3} F_{4}
\end{aligned}
$$

\section{Results and Discussion}

The SST region is divided into three parts namely epidermis (the outer one), dermis (under the epidermis) and sub dermis (below the dermis layer). The value of K, M, S are assumed constant epidermis layer in dermis layer. K, M, S and other values are calculated using Lagrange's interpolation polynomial. No blood vassals present in sub dermis so values of those parameters are taken zero.

In present paper mathematical model has been developed to analyze the temperature variation in dermal region. The total thickness is taken $0.95 \mathrm{~cm}$. The thickness of subcutaneous; dermis and epidermis are $0.50 \mathrm{~cm}, 0.35 \mathrm{~cm}$ and $0.10 \mathrm{~cm}$ respectively.

The values of physical and physiological parameters have been taken from Cooper and Trazek as given below:

\begin{tabular}{|c|c|c|}
\hline $\begin{array}{llll}\left.\min { }^{\circ} \mathrm{C}\right) & \text { Thermal Conductivity } & (\mathrm{cal} / \mathrm{cm} \\
\end{array}$ & $\begin{array}{l}\text { Heat Transfer Coefficient h }\left(\mathrm{cal} / \mathrm{cm}^{2}\right. \\
\left.\min { }^{\circ} \mathrm{C}\right)\end{array}$ & Specific Heat of Tissues c $\left(\mathrm{cal} / \mathrm{gm}^{\circ} \mathrm{C}\right)$ \\
\hline $\mathrm{K}_{1}=0.060, \mathrm{~K}_{2}=0.045, \mathrm{~K}_{3}=0.030$ & 0.009 & 0.830 \\
\hline $\begin{array}{l}\text { Blood Density of Tissues } \\
\left(\mathrm{gm} / \mathrm{cm}^{3}\right)\end{array}$ & $\begin{array}{l}\text { Latent Heat } \\
(\mathrm{cal} / \mathrm{gm})\end{array}$ & $\begin{array}{l}\text { Body Core Temperature } \\
\left({ }^{\circ} \mathrm{C}\right)\end{array}$ \\
\hline 1.090 & 579.0 & 37 \\
\hline
\end{tabular}

Table 1: Values for physical and physiological parameters

Table 2: M, S and E for different atmospheric temperature

\begin{tabular}{|l|l|l|l|}
\hline $\begin{array}{l}\text { Atmospheric } \\
\text { Temperature } \mathrm{T}_{\mathrm{a}}\left({ }^{\circ} \mathrm{C}\right)\end{array}$ & $\begin{array}{l}\text { Rate of Evaporation E } \\
\left.\mathrm{gm} / \mathrm{cm}^{2} \mathrm{~min}\right)\end{array}$ & $\begin{array}{l}\text { Blood Mass Flow Rate M } \\
\left(\mathrm{cal} / \mathrm{cm} \mathrm{min} .{ }^{\circ} \mathrm{C}\right)\end{array}$ & $\begin{array}{l}\text { Rate of metabolism } \\
\mathrm{S}\left(\mathrm{cal}^{\circ} \mathrm{cm}^{3} \mathrm{~min}{ }^{1}\right.\end{array}$ \\
\hline 23 & $0,0.24 \times 10^{-3}, 0.48 \times 10^{-3}$ & 0.0180 & 0.0180 \\
\hline 33 & $0.24 \times 10^{-3}, 0.48 \times 10^{-3}$ & 0.0315 & 0.0180 \\
\hline
\end{tabular}

Initially it is assumed that SST region is fully insulated. So temperature of each layer at time $\mathrm{t}=0$ is equal to the $37^{\circ} \mathrm{C}$.

Table 3: Nodal temperatures at different values of $q$ and at the environment temperatur $23^{0} C$

\begin{tabular}{|l|l|l|l|}
\hline$q$ & $T_{0}$ & $T_{1}$ & $T_{2}$ \\
\hline 0.96 & 32.46 & 33.67 & 35.89 \\
\hline 0.97 & 32.45 & 33.66 & 35.88 \\
\hline 0.98 & 32.44 & 33.65 & 35.87 \\
\hline 0.99 & 32.43 & 33.64 & 35.86 \\
\hline 1 & 32.41 & 32.62 & 35.86 \\
\hline 1.01 & 32.40 & 33.61 & 35.85 \\
\hline 1.02 & 32.39 & 33.60 & 35.84 \\
\hline 1.03 & 32.38 & 33.59 & 35.83 \\
\hline 1.04 & 32.37 & 33.57 & 35.82 \\
\hline
\end{tabular}

Table 4: Nodal temperatures at different values of $q$ and at the environment temperatur $33^{0} C$

\begin{tabular}{|l|l|l|l|}
\hline$q$ & $T_{0}$ & $T_{1}$ & $T_{2}$ \\
\hline 0.96 & 33.39 & 34.33 & 36.09 \\
\hline 0.97 & 33.38 & 34.32 & 36.08 \\
\hline 0.98 & 33.37 & 34.31 & 36.07 \\
\hline 0.99 & 33.36 & 34.30 & 36.06 \\
\hline 1 & 33.35 & 34.28 & 36.06 \\
\hline 1.01 & 33.34 & 34.27 & 36.05 \\
\hline 1.02 & 33.32 & 34.26 & 36.04 \\
\hline 1.03 & 33.31 & 34.25 & 36.03 \\
\hline 1.04 & 33.30 & 34.23 & 36.02 \\
\hline
\end{tabular}

Heat loss from epidermis layer is more than that of the dermis and SST region due to evaporation. Temperature variation is seen by changing the value of $\mathrm{q}$. It is observed that the fall in tissue temperature is more at same rate of evaporation and lower atmospheric temperature. Also the tissue temperature decreases with the rise in venous blood temperature. Here we see that in Table 3 and Table 4 when the temperature of 
environment will increase that time temperature of dermal region also increase at same time we also increase the value of $\mathrm{q}$ means, increase the arterial blood temp , the temp of dermal region decrease in different environmental temp. So we conclude that the temp of arterial blood is not equal to the blood temp or not equal to constant. Body temp also varied with respect to arterial blood temp i.e. it varied in study state case.

\section{References}

[1] W.PerlHeat and matter distribution in body tissue and determination of tissue blood flow by local clearance methods" journal of theoretical biology 2(3),1962,201-235.

[2] Perl,W. and Hirsch, R.L. ,Local blood flow in kidney tissue by heat clearance method, J. Theoret.Biol. 10(2), 1966, 251-280

[3] Cooper, T.E. and Trezek, G.J.,A Probe technique for determining the thermal conductivity of tissues, J. Heat transfer, ASME 94, 133-140,1972,a.

[4] Cooper, J.E. and Trezek, G.T.,on the freezing of tissues, J. Heat transfer, ASME, 94,251-253,1972,b.

[5] Patterson, A.M., Measurement of temperature profiles in human Skin, S.Afr J. Sci, 72, 78-79,1976.

[6] [6]]Saxena, V.P. and Arya, D., Steady state heat distribution in epidermis, dermis and Subcutaneous tissues" J.Theovet, Biol. 89,(1981),423-432.

[7] Saxena V.P. and Bindra J.S., Indian Journal of pure and Applied Mathematics,18(9),(1987), 846-855.

[8] Yadav , A.S., " Mathematical Study of heat flow in human skin with thermal injury” Ph.D. Thesis, J.U. Gwalior,1998.

[9] Trezek G.J. and Cooper T.E. ,Analytical determination of cylindrical source temperature field and their relation to thermal diffusivity of brain tissue, Thermal prov. in Bio-tech ; ASME, NY, 1-15,1968.

[10] Saxena, V.P. ,Application of similarity transformation to unsteady state heat migration problem in human skin and subcutaneous tissues,Proc. $6^{\text {th }}$ Int. Heat Transfer Conf. 3, 65-68,1978.

[11] Saxena V.P. and Pardasani K.R. , "Effect of dermal tumors on temperature distribution in skin with variable blood flow" Bull. Math Bio.53(4), 525-536 (1991). 